\title{
Three-Dimensional Conductive Scaffolds as Neural Prostheses Based on Carbon Nanotubes and Polypyrrole
}

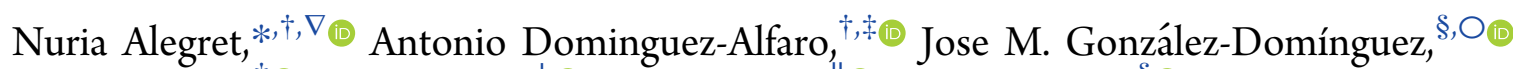

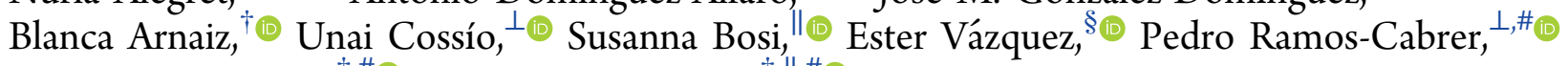
David Mecerreyes, ${ }^{*,+, \#(\infty)}$ and Maurizio Prato ${ }^{* \dagger,}, \|, \# \odot$

${ }^{\dagger}$ Carbon Nanobiotechnology Group, CIC biomaGUNE, Paseo de Miramón 182, 20014 Donostia-San Sebastián, Spain

${ }^{\ddagger}$ POLYMAT, University of the Basque Country UPV/EHU, Avenida de Tolosa 72, 20018 Donostia-San Sebastián, Spain

${ }^{\S}$ Departamento de Química Orgánica, Facultad de Ciencias y Tecnologías Químicas-IRICA, Universidad de Castilla-La Mancha, 13071 Ciudad Real, Spain

"Department of Chemical and Pharmaceutical Sciences, INSTM. University of Trieste, Via L. Giorgieri 1, 34127 Trieste, Italy

${ }^{\perp}$ Radioimaging and Image Analysis Platform, CIC biomaGUNE, Paseo de Miramón 182, 20014 Donostia-San Sebastián, Spain

"Ikerasque, Basque Foundation for Science, 48013 Bilbao, Spain

Supporting Information

ABSTRACT: Three-dimensional scaffolds for cellular organization need to enjoy a series of specific properties. On the one hand, the morphology, shape and porosity are critical parameters and eventually related with the mechanical properties. On the other hand, electrical conductivity is an important asset when dealing with electroactive cells, so it is a desirable property even if the conductivity values are not particularly high. Here, we construct three-dimensional (3D) porous and conductive composites, where C8-D1A astrocytic cells were incubated to study their biocompatibility. The manufactured scaffolds are composed exclusively of carbon nanotubes (CNTs), a most promising material to interface with neuronal tissue, and polypyrrole (PPy), a conjugated polymer demonstrated to reduce gliosis, improve adaptability, and increase charge-transfer efficiency in brain-machine interfaces. We developed a new and easy strategy, based on the vapor phase polymerization (VPP) technique, where the monomer vapor is polymerized inside a sucrose sacrificial

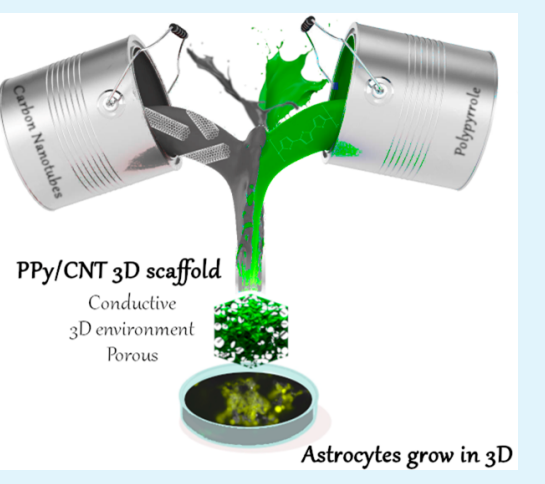
template containing CNT and an oxidizing agent. After removing the sucrose template, a 3D porous scaffold was obtained and its physical, chemical, and electrical properties were evaluated. The obtained scaffold showed very low density, high and homogeneous porosity, electrical conductivity, and Young's Modulus similar to the in vivo tissue. Its high biocompatibility was demonstrated even after 6 days of incubation, thus paving the way for the development of new conductive 3D scaffolds potentially useful in the field of electroactive tissues.

KEYWORDS: carbon nanotubes, polypyrrole, vapor phase polymerization, conjugated polymers, 3D scaffold, tissue engineering, neural prostheses

\section{INTRODUCTION}

Neurodegenerative diseases, such as Parkinson, Alzheimer, or Lateral Sclerosis, are currently irreversible and finding an ultimate or partial cure to revert their consequences is one of the pending milestones of the scientific community. ${ }^{1}$ Huge efforts are being focused on the tissue engineering research based on the neurogenesis, a brand-new concept established in the past years according to which the neurons in the peripheral nervous system are able to regenerate also in the adult stage. ${ }^{2,3}$ The key goal of tissue engineering is the development of stimulus-responsive biomaterials, also known as scaffolds, with easy-to-tailor properties that mimic the extracellular matrix of the native tissue. In this context, carbon nanotubes (CNTs) are one of the most promising materials to interface with electrically active tissues, such as the neuronal and cardiac ones. Although it is well-known that there is a correlation between cell membrane potential and cell proliferation, ${ }^{4}$ it was recently demonstrated that CNTs boost the electrical activity of neurons and, furthermore, increase the number and lengths of their neurites. ${ }^{5}$ Our group has been leading the research on the application of CNTs for nerve tissue regeneration and succeeded in the construction of two-dimensional (2D) and three-dimensional (3D) scaffolds for such purpose. ${ }^{6}$ In light of our previous results, it is clear that there is a need to develop a synthetic scaffold that would be biocompatible, immunologically inert, conductive, and infection-resistant to support cell

Received: September 20, 2018

Accepted: November 26, 2018

Published: November 26, 2018 
outgrowth and move toward future implantation in patients. $^{7-14}$ It is worth noting that the mechanisms of regeneration of the central nervous system and cardiac tissues after an injury are unclear, and some scientists assert that such regeneration is not possible. Therefore, even though traditional scaffolds are desired to be biodegradable, such as in bone tissue engineering, neuronal and cardiac regeneration may require a permanent implant as a bridge between the healthy nearby cells and restore the lost functions. In these cases, a permanent implant must not be biodegradable to accomplish its purpose in the long term.

The 3D scaffolds are of particular relevance to mimic the three-dimensional tissue structure, and thus we would expect the cellular growth, dimension disposition, and cellular connections to improve, turning the use of $3 \mathrm{D}$ implants in tissue engineering to restore the lost functionalities eventually becoming a reality. ${ }^{15}$ Such third dimension in CNT-based scaffolds could be achieved by blending with a polymeric support. The combination of CNT with numerous polymers has been extensively studied in the last years, and the materials produced showed a great potential in many different fields from biomedicine to solar cells, energy storage, and electronics. ${ }^{16}$ Polymers are used as support materials for CNTs in the form of fibers, hydrogels or solid matrix to allow one to play with the shape, dimensions, and stiffness of the final scaffold. Ideally, the inherent ability of CNTs to favor the cellular growth could be synergistically combined in a 3D scaffold with a conjugated polymeric substrate resulting in the ultimate implant for tissue regeneration of electroactive cells.

Conjugated polymers (CPs) have emerged as a novel and very promising class of electroactive biomaterial. ${ }^{17}$ The design of electrodes based on CPs in brain-machine interface technology offers the opportunity to exploit a wide diversity of materials to reduce gliosis, ${ }^{18-20}$ the most common brain response to chronically implanted neural electrodes. In fact, the use of CPs might result in electrodes with improved adaptability not only for the neuronal tissue but also for other types of electroactive tissues and increase charge-transfer efficiency. They are generally synthesized as coating of films, composites, or fibers of nonconductive materials to improve their electrical properties. ${ }^{21}$ Such versatility offers a wide range of options to modify their chemical, biological, and physical properties, thus becoming very important materials for biosensors, neural prostheses, drug delivery devices and tissue engineering scaffolds. ${ }^{22,23}$

Polypyrrole (PPy) is among the most used and studied CPs for bioapplications, ${ }^{24,25}$ although, as common in most CPs, its non-soluble nature in water only allows PPy to be processed as coatings or doped with stabilizing agents, such as PSS. Its conductive nature and high biocompatibility make it an outstanding material to develop scaffolds not only to be used as electrodes for recording or stimulating cell behavior but also for an improved cell growth without any external stimulus. ${ }^{18,26,27}$ PPy has been used to provide electrical properties to non-conductive $3 \mathrm{D}$ structures, by coating polymeric films onto previously synthesized non-conductive electrospun fibers, such as collagen or PLLA. ${ }^{28-34}$ However, very little is reported about the combination of PPy and CNTs, being most of the works related to the development of $2 \mathrm{D}$ films. ${ }^{27,35-38}$ To the best of our knowledge, a tridimensional structure purely composed of PPy and CNT has never been synthesized before.

In the present work, we succeeded in the construction of $3 \mathrm{D}$ porous composites formed exclusively of PPy and CNTs, and incubated astrocytic cells to evaluate its biocompatibility. We have developed a new and easy strategy, based on the wellknown vapor phase polymerization (VPP), ${ }^{39}$ where pyrrole monomer vapor is polymerized inside a template-containing CNT and an oxidant agent. Astrocytes, which form part of the glia, provide support and nutrients to neurons in a healthy environment, thus have an essential function in the regeneration of neuronal tissue. Furthermore, they propagate intercellular $\mathrm{Ca}^{2+}$ in response to stimulation and release transmitters, ${ }^{40}$ thus being an ideal model to test the biocompatibility and the potential of our conductive scaffolds in neural prostheses. Our final goal is the manufacture of permanent implants, producing no harm or inflammation in the long term, able to provide the lost conductivity after, for example, brain or spinal cord injury, where a glial insulating scar might be formed, thus hindering the neuronal function and communication between the nearby healthy tissues. Therefore, we designed a nondegradable scaffold, taking advantage of the nondegradability of PPy and CNT, to act as a conductive-communicating bridge between the nearby healthy tissues. The resulting material is a very promising scaffold with very low density, good porosity, and high biocompatibility, thus paving the way for the development of new conductive $3 \mathrm{D}$ scaffolds by following a yet unexploited approach.

\section{EXPERIMENTAL SECTION}

Materials and Methods. Multiwalled carbon nanotubes (CNTs, 99\%) were purchased from Nanoamor Inc. (Stock\# 1237YJS). Pyrrole (Py, 98\%) was purchased from Sigma-Aldrich. Iron(III) chloride hexahydrated $\left(\mathrm{FeCl}_{3} \cdot 6 \mathrm{H}_{2} \mathrm{O}\right)$ was acquired from Fisher Scientific Inc. Ethanol (synthesis grade) was purchased from Carlo Erba Reagents SAS. All reagents and solvents were used as received with no further purification.

Thermogravimetric analyses were performed under air $(25 \mathrm{~mL}$. $\mathrm{min}^{-1}$ flow rate) using a TGA Discovery (TA Instruments). The samples were equilibrated at $100{ }^{\circ} \mathrm{C}$ for $20 \mathrm{~min}$ and then heated at a rate of $10{ }^{\circ} \mathrm{C} \cdot \mathrm{min}^{-1}$ in the range from 100 to $800{ }^{\circ} \mathrm{C}$. Scanning electron microscope (SEM) measurements were performed on JEOL JSM-6490LV at $5 \mathrm{kV}$, running in a point by point scanning mode. Transmission electron microscope (TEM) was carried out on JEOL JEM-2100F model EM-20014, which features a $200 \mathrm{kV}$ field emission gun (Schottky, FEG) and an ultrahigh resolution (UHR) pole piece. Mechanical characterization was performed with a Mecmesin MultiTest 2.5-i dynamic mechanical analyzer, using a $50 \mathrm{~N}$ load cell and Teflon-covered steel plates as holders. The conductivity was evaluated through the electrochemical impedance spectroscopy (EIS) using frequencies in the range from 0.1 to $100.000 \mathrm{~Hz}$, with an electrochemical workstation Autolab MSTAT204 Potentiostat/ Galvanostat.

Microcomputed tomography ( $\mu$-CT) was used to quantify the porosity of CNTs and PPy based scaffolds. High-resolution $\mu$-CT scans were performed on a SkyScan $1172 \mu$-CT system (Bruker $\mu$-CT, Kontich, Belgium) at an energy and intensity level corresponding to $29 \mathrm{kV}$ voltage and $175 \mu \mathrm{A}$ current for 1200 projections. Particle analysis toolbox in ImageJ was used to determine the pore size distribution of the scaffolds. Image processing protocol has been developed to assess scaffolds' surface porosity, pore size distribution, and internal canalizations.

Mouse astrocyte C8-D1A cell line was purchased from ATCCLGC and cultured in phenol red-free DMEM media (GIBCO) completed with $2 \mathrm{mM}$ L-glutamine (Gibco), $100 \mathrm{U} \cdot \mathrm{ml}^{-1}$ penicillin, $100 \mu \mathrm{g} \cdot \mathrm{mLl}^{-1}$ streptomycin (Gibco), $1 \mathrm{mM}$ sodium pyruvate, and $10 \%$ heat-inactivated fetal bovine serum (Gibco). The phosphate buffer saline (PBS) was purchased in tablets and prepared following manufacturer procedures (Sigma-Aldrich) corresponding to $10 \mathrm{mM}$ PBS containing $137 \mathrm{mM} \mathrm{NaCl}$ and $2.7 \mathrm{mM} \mathrm{KCl}$ at $\mathrm{pH}$ 7.4. 
Three-Dimensional Scaffolds: Synthesis and Characterization. The 3D scaffolds were produced through a multistage process similar to the one described elsewhere. ${ }^{6}$ Food-approved sucrose $(250 \mathrm{mg})$ was ground and passed through two mesh sieves with pore sizes of 250 and $100 \mu \mathrm{m}$, respectively (Fisher Scientific Inc.); the fraction collected was the one remaining in the middle of both, thus ensuring a grain size between 100 and $250 \mu \mathrm{m}$. CNTs $(7.5$ $\mathrm{mg}$ ) and the sieved sucrose $(250 \mathrm{mg})$ were then mixed in dry conditions and shaken overnight. Later, 10, 20, or $40 \mathrm{mg}$ of $\mathrm{FeCl}_{3}$. $6 \mathrm{H}_{2} \mathrm{O}$ were added, corresponding to $3 \%, 7 \%$, and $13 \%$ of the total mass of the template, respectively, (labeled as ox-3\%, ox- $7 \%$, and ox$13 \%$, respectively, in the next sections) and mixed in dry conditions until obtaining a homogeneous solid powder. Finally, $5 \mu \mathrm{L}$ of Milli-Q water was added and the blend was mixed until a homogeneously wet material was obtained. The mixture was poured into a hollow plastic cylinder of $5 \mathrm{~mm}$ in diameter and gently pressed from both sides to form a cylindrical-shape template. Then the template was hanged with a thread inside a Schlenk flask, which was afterwards filled with argon. Subsequently, $0.5 \mathrm{~mL}$ of pyrrole monomer was introduced at the bottom of the Schlenk flask, and the VPP was carried out varying two conditions: temperature $\left(60,80\right.$, or $\left.100{ }^{\circ} \mathrm{C}\right)$, and time of reaction $(2$ or $16 \mathrm{~h}$ ). The polymer was deposited into the interstitial cavities of the template. Once the polymerization was completed, the cylinder was immersed overnight into Milli- $Q$ water to remove the excess oxidant and dissolve the sucrose, resulting in a cast framework made of connected empty cavities of controlled shape and dimensions. Finally, using a Soxhlet system the scaffold was cleaned with ethanol for 2 days to remove the side products and free PPy oligomers.

The synthesis and characterization of the PDMS/CNT scaffolds used as controls in this work was reported previously. ${ }^{41}$

Microcomputed Tomography $(\mu-C T)$. Scaffolds were isolated from the background, using a thresholding procedure that was specific to this material. The values to segment the scaffold from background were optimized comparing the $2 \mathrm{D}$ gray scale image of a single slice with the thresholded image. In this way, binary images were created and porosity values for each slice were assessed. Porosity values were determined as the percentage of pores' area with respect to the total area. Because the material is highly homogeneous, porosity was calculated in 10 randomly selected slices within the scaffold $(n=10)$.

Image Processing for the Pore Size Distribution. Micro-CT images were binarized using an optimized threshold and subjected to processing steps such as dilation, erosion, and watersheding. To analyze the pore distribution, the area of each pore was measured, and the equation of a circle was used to estimate an approximate value of the diameter of the pore, according to eq 1

$$
\text { Pores }=2 x\left(\sqrt{\frac{A_{\text {circle }}}{\pi}}\right)
$$

Due to the high homogeneity of the system, the pore size distribution was calculated in $n=102 \mathrm{D}$-images randomly selected along the $3 \mathrm{D}$ object.

Conductivity Analyses. The scaffolds were cut into cylinders of $5 \times$ $5 \mathrm{~mm}(\mathrm{~L} \times \mathrm{D})$, immersed in PBS) $(10 \mathrm{mM})$ and degassed for $5 \mathrm{~min}$ to ensure the complete permeation of the inner porous structure. To carry out the measurements, a particular cell was designed and manufactured consisting on a sandwich of two coplanar gold electrodes and a PDMS block in between (see Figures 1 and S1). The PDMS block has a $6 \mathrm{~mm}$ hole in the middle to accommodate the scaffolds inside, and the same thickness as them $(5 \mathrm{~mm})$ to maintain its full contact with the electrodes along the experiment. The scaffolds were then placed within the PDMS container and $0.5 \mathrm{~mL}$ of PBS was added. The relative impedance and the charge transport behavior of $\mathrm{PPy} / \mathrm{CNT}$ scaffolds were obtained by comparison with PDMS/CNT and PPy scaffolds. PDMS was fixed on the bottom Au electrode, and no leaking of the PBS solution was observed during the experiments.

Mechanical Properties. Prior to mechanical testing, the scaffolds were soaked in Milli- $Q$ water for 1-2 min and the external surplus water was carefully removed with a piece of Kimwipes. Uniaxial compressive tests were performed under ambient conditions to the

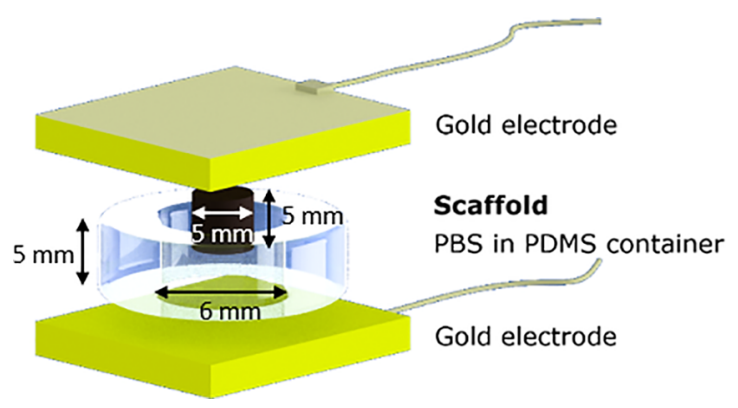

Figure 1. Schematic representation of the cell used to evaluate the tridimensional conductivity of the scaffolds developed via EIS.

wet scaffold, as it would represent a more realistic situation toward their envisioned fate, at a rate of $15 \mathrm{~mm} \cdot \mathrm{min}^{-1}$ until reaching a $90 \%$ compressive strain. The extent of the deformation was measured by relating the measured height at each moment of the analysis with the scaffold's initial height (strain, in \%). The obtained force curve was normalized to the specimens' initial diameter (stress, in $\mathrm{kPa}$ ). Young's modulus was then obtained as the slope of the linear elastic section in the initial stages (typically from 15 to $40 \%$ strain in our case). At least 4-5 repetitions of each sample were measured.

Biocompatibility Assay. Before the in vitro assays, the scaffolds were dipped in Milli- $Q$ water several times in order to ensure the removal of ethanol from the cleaning step. Then, they were left to dry in air and cut into thin disks of $2 \mathrm{~mm}$ thickness. PDMS/CNT disks were cleaned under low-pressure oxigen plasma for $6 \mathrm{~min}$ (Pico Plasma Cleaner, Diener electronic) each side. Then, all the scaffolds were UV-sterilized on each side for $20 \mathrm{~min}$.

Cell Culture and Counting. C8-D1A cells were cultured in complete media at $37{ }^{\circ} \mathrm{C}$ and $5 \% \mathrm{CO}_{2}$ in tissue culture-treated 75 $\mathrm{cm}^{2}$-flasks (Nunc). For cell passage, cells were detached from the flasks by incubation at $37^{\circ} \mathrm{C}$ with trypsin-EDTA solution $1 \times(2.5 \mathrm{~g}$ of porcine trypsin and $0.2 \mathrm{~g}$ of EDTA.4Na per liter of Hanks' Balanced Salt, Sigma) and spun at $10^{3}$ RCF for 5 min; the obtained pellet was resuspended in $1 \mathrm{~mL}$ of complete media and disaggregated. For cell counting, the cell suspension was serially diluted 1:10 in PBS and 1:2 in the exclusion dye Trypan Blue solution $(0.4 \%$ in $0.81 \%$ sodium chloride and $0.06 \%$ potassium phosphate, dibasic, Sigma). Ten microliters of the diluted cell suspension was counted in a hemocytometer chamber under transmitted light in an inverted microscope (DMIL, Leica). All the 3D scaffolds were transferred to a 96-well sterile plate and incubated in $200 \mu \mathrm{L}$ of complete media for 2 $\mathrm{h}$ at $37^{\circ} \mathrm{C}$ and $5 \% \mathrm{CO}_{2}$. For cell seeding, the media was removed by aspiration and $20-50 \mu \mathrm{L}$ of complete media containing $5 \times 10^{5}$ or $5 \times$ $10^{3}$ C8-D1A cells was added carefully onto the scaffolds. The wells were filled by slowly adding $150 \mu \mathrm{L}$ of complete media and incubated for 2 or 6 days at $37{ }^{\circ} \mathrm{C}$ and $5 \% \mathrm{CO}_{2}$.

$L D H$ Assay. The viability of cells grown on the scaffolds was evaluated with the modified LDH CytoTOX96 Non-Radioactive Cytotoxicity Assay kit (Promega) reported by Ali-Boucetta et al. ${ }^{42}$ For cell lysis, scaffolds were transferred to a 96-well U bottom plate and mechanically disrupted by smashing after addition of $150 \mu \mathrm{L}$ of PBS containing 9\%Triton X-100 (lysis buffer, LB). Then, the samples were frozen at $-80{ }^{\circ} \mathrm{C}$ for $30 \mathrm{~min}$, defrosted for $20 \mathrm{~min}$ at $37^{\circ} \mathrm{C}$, and disrupted again. The CNT-PPy-based material was separated by centrifugation at $10^{3} \mathrm{RCF}$ for $10 \mathrm{~min}$ at $4{ }^{\circ} \mathrm{C}$ and supernatants were transferred to empty wells. For the $\mathrm{LDH}$ detection, $50 \mu \mathrm{L}$ of each supernatant was mixed with $50 \mu \mathrm{L}$ of substrate mix, and after $4 \mathrm{~min}$ the reaction was terminated by the addition of $50 \mu \mathrm{L}$ of stop solution. Absorbance measurements at $492 \mathrm{~nm}$ were taken in a microplate spectrophotometer (GeniosPro, Tecan). Positive control diluted in LB 1:5000 was included as an internal control (not shown), and LB alone was used as negative control (not shown). All the collected data is represented as means of quadruplicates $\pm \mathrm{SD}$.

Fluorescence Staining of Viable Cells. Calcein-AM (Molecular Probes) staining was performed to fluorescently labelled live cells. The scaffolds with cells were transferred to empty wells and incubated 


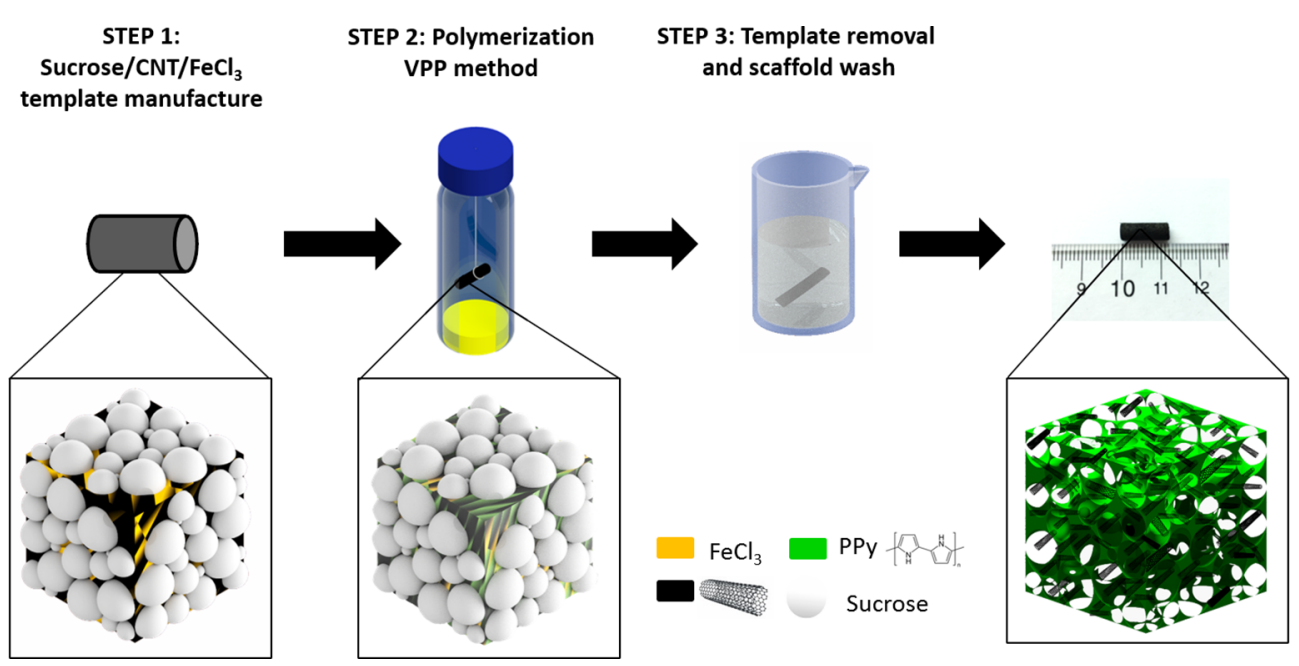

Figure 2. Schematic representation of the template manufacturing, polymerization, and final removal of sugar and biproducts to obtain the selfstanding PPy/CNT 3D scaffold.
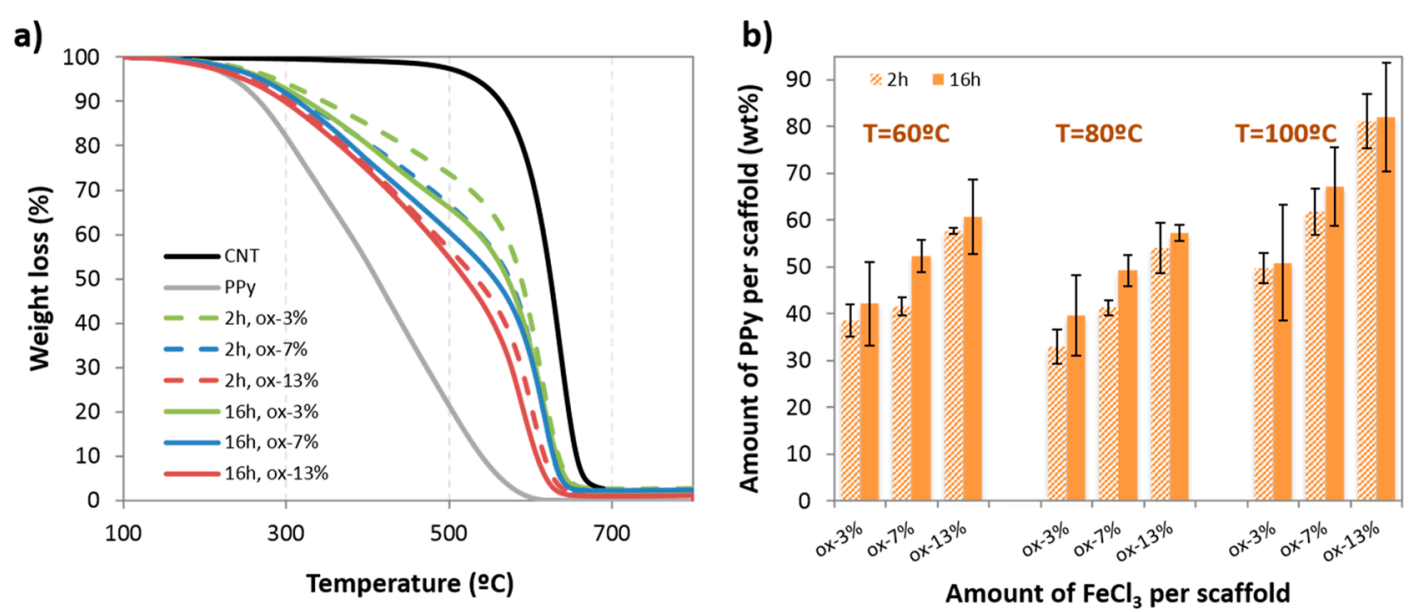

Figure 3. (a) TGA plots of the polymerization performed at $80{ }^{\circ} \mathrm{C}$ for $2 \mathrm{~h}$ (dashed) or $16 \mathrm{~h}$ (solid) using different amount of oxidant. (b) Summary of the TGA results for the experiments performed at different temperatures (see data in the SI). Error bars indicate standard deviation after at least three repetitions.

at $37^{\circ} \mathrm{C}$ for 30 min with $200 \mu \mathrm{L}$ of complete media containing $2.5 \mu \mathrm{g}$. $\mathrm{ml}^{-1}$ of Calcein-AM.

F-Actin Stain for Cell Morphology Imaging. The scaffolds incubated with cells were transferred to empty wells, washed once with $200 \mu \mathrm{L}$ of PBS, fixed with $4 \%$ paraformaldehyde in PBS for 20 min at $20{ }^{\circ} \mathrm{C}$, and washed twice with PBS. Then, they were permeabilized with $0.2 \%$ Triton X-100 in PBS for $20 \mathrm{~min}$ at $37{ }^{\circ} \mathrm{C}$. For cell F-actin filament staining, the scaffolds were incubated at 37 ${ }^{\circ} \mathrm{C}$ for $30 \mathrm{~min}$ in $200 \mu \mathrm{L}$ of media with ActinGreen488 (1:10, Molecular Probes) and washed twice with PBS before imaging.

Confocal Imaging. Scaffolds with stained cells were placed in a 50 $\mathrm{mm}$ diammeter $\neq 1.5$ optical glass-bottom-Petri dish (Mattek) with a drop of PBS onto each scaffold disk. Images were taken in a $1 \mathrm{sm} 880$ confocal microscope (Zeiss) employing excitation at $633 \mathrm{~nm}$ and detection between 615 and $663 \mathrm{~nm}$ in the reflection mode for scaffold imaging, and excitation at $488 \mathrm{~nm}$ with detection between 500 and $610 \mathrm{~nm}$ for Calcein-AM stained cells or ActinGreen stained cells. For live imaging, the drop of PBS contained $2.5 \mu \mathrm{g} \cdot \mathrm{ml}^{-1}$ Calcein-AM, and a microscope insert chamber was employed at $37^{\circ} \mathrm{C}, 5 \% \mathrm{CO}_{2}$, and $100 \%$ humidity.

\section{RESULTS AND DISCUSSION}

Preparation of 3D Conductive Scaffolds by Vapor Phase Polymerization (VPP). Figure 2 shows a schematic representation of the manufacturing process of the conductive PPy and CNTs scaffolds. Briefly, a cylindrical template made of sieved sucrose (granularity between 100 and $250 \mu \mathrm{m}$ ), multiwalled pristine $\mathrm{CNTs}$ and $\mathrm{FeCl}_{3} \cdot 6 \mathrm{H}_{2} \mathrm{O}$ was hanged inside an Ar-filled schlenck. Then pyrrole monomer was introduced at the bottom and the flask was warmed-up to temperatures below to the boiling point of the monomer $\left(131^{\circ} \mathrm{C}\right)$. The polymerization reaction, based on the VPP method, took place inside the cylinder template, where pyrrole vapor was oxidized, polymerized, and deposited within the interstitial cavities left by the sucrose template and the CNTs. Finally, in the cleaning step the sucrose and the side-products were removed by immersion into water first and into ethanol afterward. The complete removal of $\mathrm{Fe}$ and $\mathrm{Cl}$ was confirmed by XPS analyses (see Supporting Information). As a result, a self-standing cylindrical porous template only composed of PPy and CNTs was obtained.

Next, we focused our efforts in understanding how the conditions of the PPy polymerization step may affect the properties of the final scaffold. Thus, we kept constant the amount of nanotubes to reduce the experimental methodology down to three variables: (i) temperature was set at 60,80 , or 

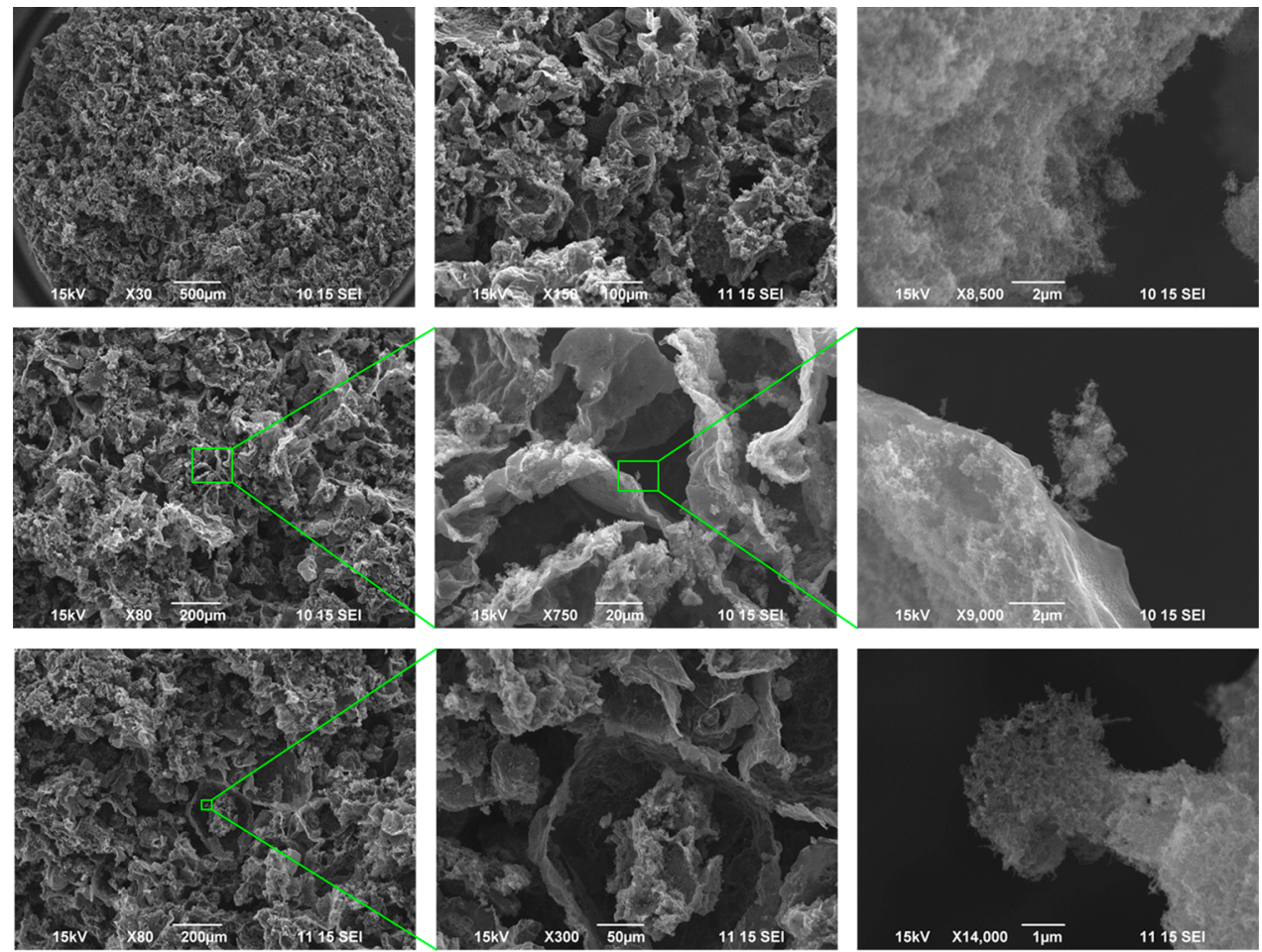

Figure 4. SEM micrographs of the $3 \mathrm{D}$ scaffolds (synthesized at $80{ }^{\circ} \mathrm{C}$ with ox-7\% for $16 \mathrm{~h}$ ).

$100{ }^{\circ} \mathrm{C}$; (ii) reaction times were of 2 or $16 \mathrm{~h}$, and (iii) the amount of $\mathrm{FeCl}_{3} \cdot 6 \mathrm{H}_{2} \mathrm{O}$ oxidant added was the $3 \%, 7 \%$ or $13 \%$ of the total weight of the scaffold (named from now on ox-3\%, ox- $7 \%$, and ox- $13 \%$, respectively). After reactions, the obtained scaffolds were characterized by thermogravimetric analysis (TGA) to elucidate the amount of polymer versus the amount of CNTs. The measurements were performed under air because these conditions allow to distinguish between polymer and CNT degradations. We have confirmed that the polymerization, thus the amount of polymer, along the whole 3D structure is homogeneous after analyzing several sections of the same scaffold with TGA; the related data are shown in the Supporting Information. Figure 3 a gathers the TGA curves obtained for the scaffolds synthesized at $80{ }^{\circ} \mathrm{C}$, pristine CNT, and the pristine polymer; the plot represents the average results obtained for three scaffolds synthesized under the same conditions. Whereas PPy decomposes between 200 and 600 ${ }^{\circ} \mathrm{C}$, the CNTs start decomposing at $500{ }^{\circ} \mathrm{C}$ under air. Thus, $500{ }^{\circ} \mathrm{C}$ was taken as the reference temperature to calculate the amount of PPy, considering that at such temperature the $80 \%$ of the polymer has been already decomposed while the CNTs remain almost intact (see Figure 3a). In most cases, the resulting plot indicates that the scaffold is mainly composed by CNT in a range between $45 \%$ and $70 \%$. The plots for the scaffolds synthesized at 60 and $100{ }^{\circ} \mathrm{C}$ are displayed in the Supporting Information.

Figure $3 \mathrm{~b}$ displays the average results obtained from the variation of the three variables analyzed: temperature, time, and amount of oxidant. The effect of each variable in the formation of the polymer can be summarized as follows: (i) an increase of the amount of oxidant, regardless of the polymerization time and temperature, produces an increase in the average amount of PPy obtained. In general terms, double amount of oxidant produces an increase in the amount of polymer within the scaffold between $3 \%$ and $20 \%$ in weight. (ii) There is no significant effect of the temperature between 60 and $80{ }^{\circ} \mathrm{C}$, the resulting amount of PPy synthesized is in the same range: $30-40 \%$ of PPy for ox-3\%; $41 \%$ for ox- $7 \%$ and $55 \%$ for ox- $13 \%$ after $2 \mathrm{~h}$ of reaction; $40 \%, 50 \%$, and $60 \%$ for ox-3\%, ox-7\%, and ox-13\%, respectively after $16 \mathrm{~h}$ of polymerization. On the other hand, these values increase when the polymerization is carried out at $100{ }^{\circ} \mathrm{C}$, being the ranges of $\mathrm{PPy}$ around $50 \%$ for ox-3\%, 65\% for ox-7\%, and about $80 \%$ for ox-13\%. (iii) The polymerization time is relevant at low temperatures; larger time increases the amounts of polymer synthesized, as observed for 60 and $80{ }^{\circ} \mathrm{C}$ (see Supporting Information). However, this effect is not observed for $100{ }^{\circ} \mathrm{C}$, suggesting that at high temperatures the evaporation of the monomer is produced during the first 2 $\mathrm{h}$, whereas after that time the remaining monomer at the bottom of the flask might not be preserved in its original state and might not actively participate in the VPP process. Thus, the saturation degree of the polymerization might be achieved faster at that temperature.

In summary, different scaffolds with varying $\mathrm{CNT} / \mathrm{PPy}$ ratio could be synthesized using the VPP method. We observed that such ratio is directly related to the amount of oxidant used per scaffold, the time, and the temperature of the reaction. Thus, by varying the main conditions of the polymerization reaction, we are able to control the amount of polymer present in the final scaffold and, we anticipate, their properties.

Macro- and Nanostructure Imaging and Pore Size Distribution. In our method, the pore size and porosity should be defined by the sucrose used as porogen or sacrificial template. Upon removal the water driven dissolution of sugar grains produced macro-pores inside the polymeric scaffold of irregular shapes, mimicking living tissue's irregular geometries. Pore connections were the consequence of the aggregation of sugar grains along their contact points via water driven consolidation process. The SEM pictures shown in Figure 4 
reveal the porous structure of the as-synthesized 3D scaffolds at $80{ }^{\circ} \mathrm{C}$ for $16 \mathrm{~h}$ using ox-7\%, composed of irregularly shaped and sized pores interconnected by random paths. Interestingly, the porosity homogeneity along the whole structure can be appreciated. Similar results were obtained for the scaffolds synthesized through other conditions; SEM images for other cases are presented in the Supporting Information for comparison.

Pore sizes of the lowest magnification $(\times 30)$ were measured using the Image software. An average of seven different synthetic conditions were measured and are plotted in Figure 5. Only pores larger than $50 \mu \mathrm{m}$ were considered. The results

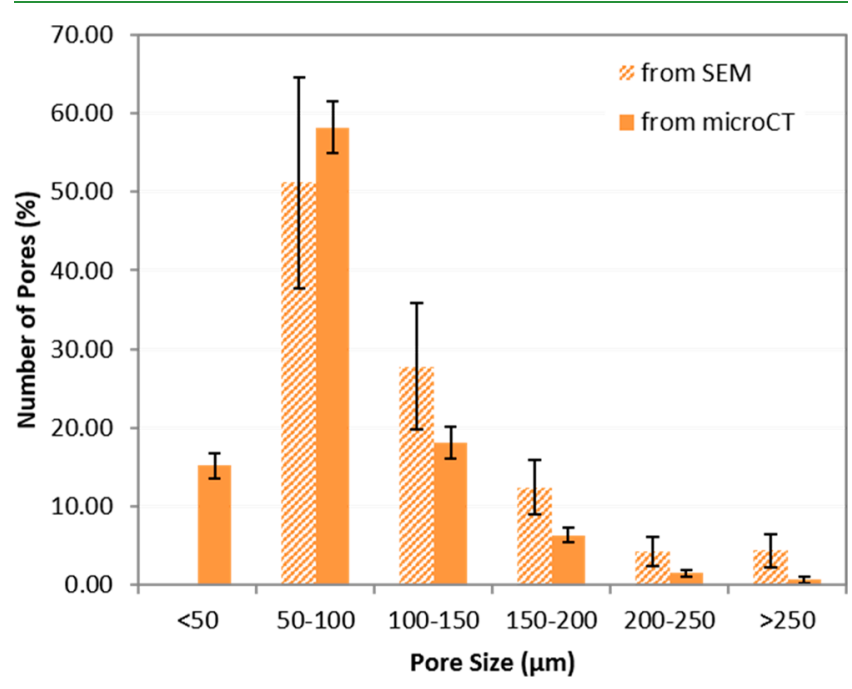

Figure 5. Pore size distribution from SEM (orange stripes) and $\mu$-CT (solid orange) analyses.

show that nearly half of the pores have sizes below the cutoff employed for the sucrose granularity $(100 \mu \mathrm{m})$, which can be explained by two factors: (i) when the sucrose/CNT mixture is blended with the oxidant, most of the grains are ground into smaller particles; (ii) such pores do not come from the dissolved sucrose grains but are formed within the polymerized PPy layers. Almost $45 \%$ of the pores have the dimensions defined by the sucrose grains, ranging between 100 and 250 $\mu \mathrm{m}$. Pores above $250 \mu \mathrm{m}$ are also observed, which can be explained due to the merging of two or more sucrose grains when water is added to build the template.

To get a further insight into the $3 \mathrm{D}$ structure of the scaffolds, the same sample was analyzed by Micro-Computed Tomography ( $\mu$-CT), shown in Figure 6 . The surface porosity value of these polymeric and CNT scaffolds was found to be $57.17 \pm 1.16 \%$ ( $n=10$ slices $)$. This means that close to $60 \%$ of the sample's area corresponds to pores and $40 \%$ to matter matching the initial sucrose loading in the scaffold. Note the small standard deviation among slices, which reflects the homogeneity of the object and supports the random selection of a finite number of $2 \mathrm{D}$ slices for image analysis. The analysis of $\mu$-CT images determined macro-pore sizes between 20 and $300 \mu \mathrm{m}$ for PPy/CNT scaffolds. As plotted in Figure 5, almost $60 \%$ of the pores had a pore size between 50 and $100 \mu \mathrm{m}$. Close to $20 \%$ of the pores had a pore size between 100 and $150 \mu \mathrm{m}$ and $15 \%$ ranged between 20 and $50 \mu \mathrm{m}$ (see Supporting Information for a higher size resolution histogram).

In order to understand how PPy polymerizes inside the scaffolds and its interaction with the CNT at the nanoscale, the scaffolds were ground and dispersed in water for TEM observation. The micrographs, collected in Figure 7a,b, show bundles of CNTs-PPy and pristine CNTs along the scaffold structure. Higher magnifications reveal that only few CNTs might be coated by the polymer (Figure $7 \mathrm{c}, \mathrm{d}, \mathrm{e}$ ); most of the tubes analyzed have thicknesses within the range of the pristine CNT provided by the supplier $(20-30 \mathrm{~nm})$. Thicknesses up to about $46 \mathrm{~nm}$ were found, suggesting that the maximum thickness of the PPy-coating-CNT might be between 8 and 16 $\mathrm{nm}$. On the other hand, the cluster pieces found in some regions (indicated with the green arrows in Figure $7 b, c, e$ and dashed lines in Figure 7d), which we assume to be bulk PPy, possibly acting as the "sticker" for the CNTs, keeping the 3D structure of the whole scaffold. Such bulk appears to be composed of few or numerous polymer layers, as shown in Figure $7 \mathrm{f}, \mathrm{g}$, respectively.

Overall, by TEM visualization we have been able to ascertain the state of dispersion and CNT-polymer interplay within our scaffolds. Instead of a continuous and uniform coating, the approach presented herein results in a random distribution of coated and uncoated CNTs, together with thick multilayered PPy clusters scattered across the structure, which we postulate that behave as brackets for CNT, thus being responsible for underpinning the structural integrity of these porous scaffolds.

Mechanical and Electrical Properties Characterization. The mechanical properties of the scaffolds should ideally mimic those of the body tissues. For this reason, Young's Modulus (YM) of our porous materials was evaluated through compression experiments of the wet scaffolds. From all the results obtained, the outliers were discarded using the interquartile method. Furthermore, the error bars were turned into confidence intervals by applying the t-student methodology with a $95 \%$ of certainty $(\alpha=0.05)$. Figure 8 gathers the

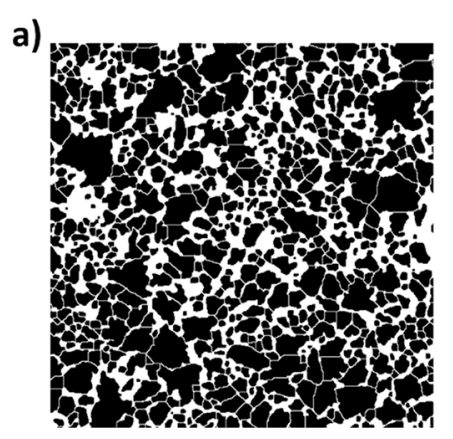

b)

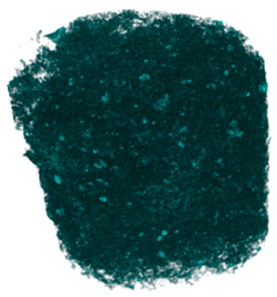

c)

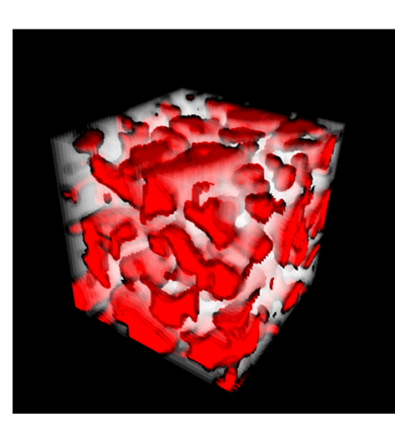

Figure 6. (a) Transversal $\mu$-CT binarised image (2D), where pores are represented in black color and matter (scaffold) in white. (b) Whole scaffold's 3D volume rendered image. (c) The 3D illustration of scaffold's pore distribution; pores are represented in red color and matter in white. 

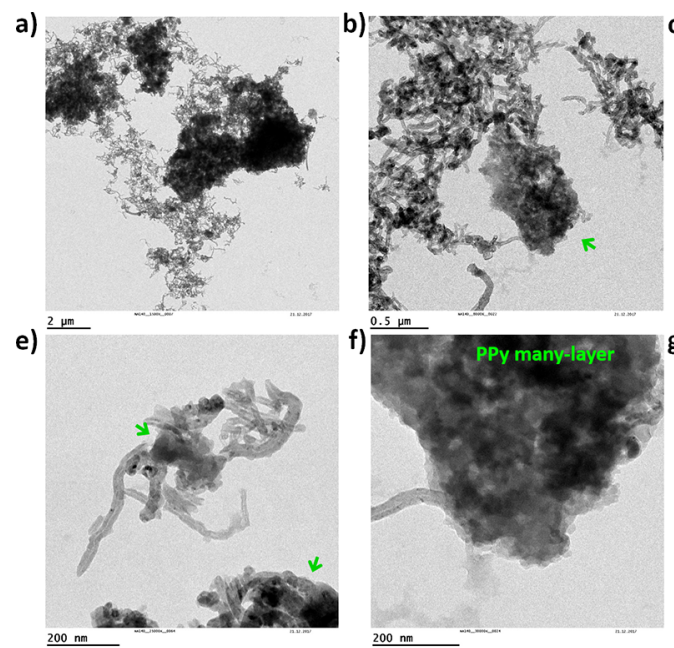
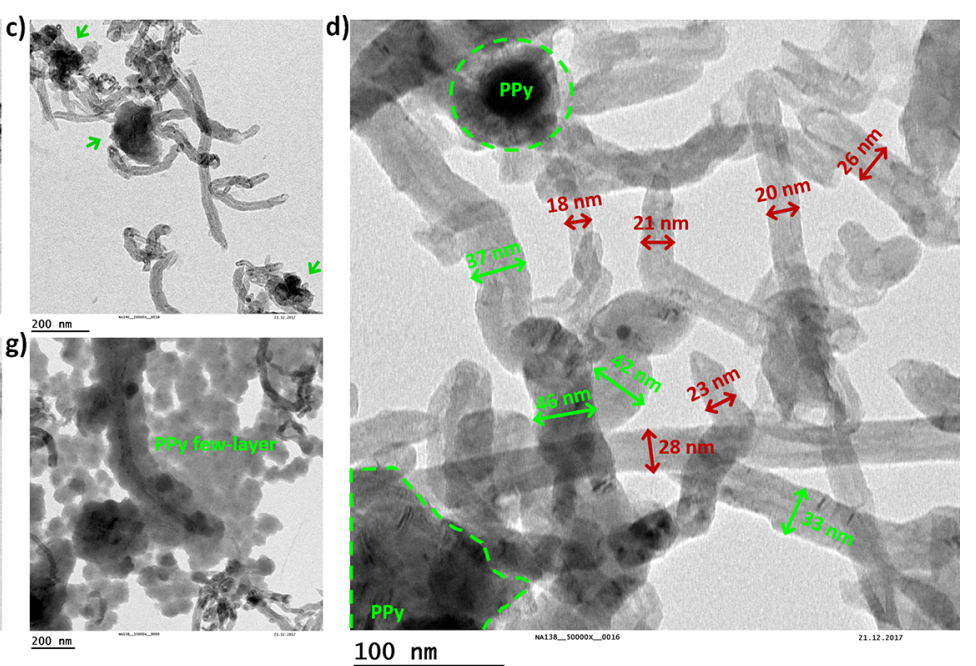

Figure 7. TEM micrographs of the CNT polymerized with PPy, from 3D scaffolds synthesized (entries 13 and 14 in Table S1). Green arrows in $(b, c, e)$ indicate the bulk PPy "stickers". (d) Red arrows show nanotubes with diameters within the pristine range $(20-30 \mathrm{~nm})$; green arrows indicate tubes with larger diameters than the pristine CNT. PPy clusters are marked with green dashed lines.

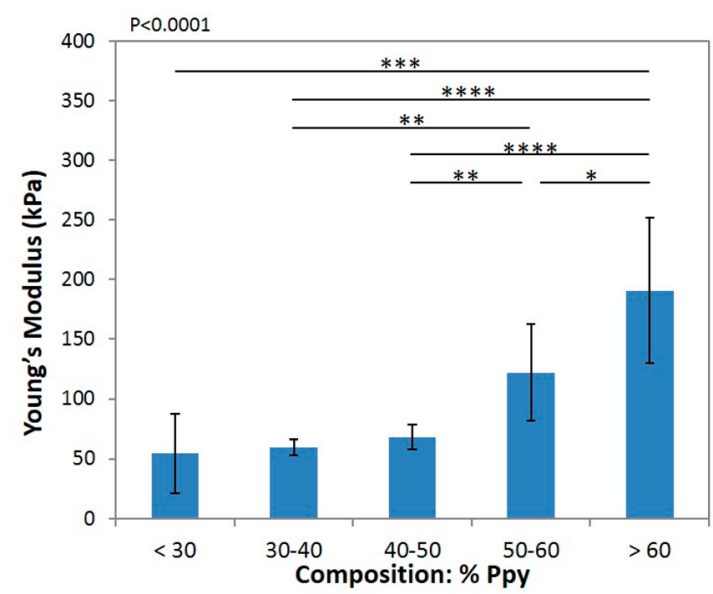

Figure 8. Young's Modulus related to the polymer composition. Statistical analyses with ANOVA.

results obtained, relating the YM to the amount of polymer present in the scaffold. A representative cyclic compression graph for each group is shown in Figure S7. At first glance, it is observed that the polymer increases the rigidity of the scaffold. There is a clear exponential relationship between the two variables, having larger YM for larger amounts of PPy synthesized within the scaffold. Interestingly, below $50 \%$ of PPy the increase in the YM value is not very significant, being in a range between 50 and $70 \mathrm{kPa}$. However, from $50 \%$ on, the sample becomes noticeably more rigid, and the obtained scaffolds present values between 100 and $200 \mathrm{kPa}$. Some of our scaffolds present similar softness to previous cross-linked hybrid hydrogels used for neuronal regeneration, which showed compressive moduli between 30 and $50 \mathrm{kPa}^{43}$ These values are within the pool of typical soft porous scaffolds used for this purpose, which warrants the suitability of our scaffolds to mechanical properties requirement for neural prostheses. The brain tissue has been determined to have YM around $2 \mathrm{kPa}$, whereas the spinal cord has been shown to have elastic modulus around $40 \mathrm{kPa}^{44,45}$ thus, in the following sections, we have analyzed those scaffolds with less than $50 \%$ of PPy, which are the ones that present closer YM to the biological tissues of interest. It is worth noting that the attempts to reduce the YM using the above-described methodology have failed because the minimum amount required of $\mathrm{PPy}$ to maintain the $3 \mathrm{D}$ structure is about $30 \%$, which results in $\mathrm{YM}$ of around $50 \mathrm{kPa}$.

One of the main purposes of manufacturing PPy/CNT composites is the improvement of the conductivity. The scaffolds that aimed to repair, for example, neural nerves not only must mimic the physiological environment but also possess electrical conductivity to promote neurite outgrowth, thereby enhancing nerve regeneration. ${ }^{46}$ Therefore, we have studied the capability of the charge transfer within a tridimensional structure using electrochemical impedance spectroscopy (EIS). Furthermore, the electrochemical impedance is an important parameter for bioapplications: implants, scaffolds, or biosensors require electronic capability in contact with cells or tissue to record physiological and pathological signals or to electrically stimulate them. It is worth to remark that recently a large number of publications have used this technique to evaluate the $3 \mathrm{D}$ conductivity of conductive polymeric scaffolds and it was also seen that CP lower the electrical impedance of metal electrodes. ${ }^{4-51}$ For our purpose, PPy/CNT scaffolds with a conductive PPy polymer matrix were compared with PPy scaffolds without the presence of CNTs and a previously reported PDMS/CNT scaffold with an insulating PDMS matrix. ${ }^{6}$ All the scaffolds measured had the same cylindrical geometry and dimensions $(5 \times 5 \mathrm{~mm}, \mathrm{~L} \times \mathrm{D})$ and were degassed in PBS to avoid any gas-molecule interference during the measurements. Thus, once placed inside the designed container (see Figure 1 and Materials and Methods) and filled with PBS solution, the scaffolds were in full contact with the bottom Au electrode. The device was designed with a PDMS framework of the same height as the scaffolds to ensure a full contact with the top Au electrode.

As observed in Figure 9, the impedance of PPy/CNT scaffolds $\left(\left|Z_{\mathrm{PPy} / \mathrm{CNT}}\right|=7.8 \mathrm{k} \Omega\right)$ at $0.1 \mathrm{~Hz}$ was approximately four and seven times lower than that of PPy $\left(\left|Z_{\mathrm{PPy}}\right|=30 \mathrm{k} \Omega\right)$ and PDMS/CNT $\left(\left|Z_{\mathrm{PDMS} / \mathrm{CNT}}\right|=50 \mathrm{k} \Omega\right)$, respectively, and one order of magnitude lower than the gold electrodes measured in PBS solution $\left(\left|Z_{\mathrm{PBS}}\right|=90 \mathrm{k} \Omega\right)$. We suggest that the lowest impedance of $\mathrm{PPy} / \mathrm{CNT}$ comes from the formation of 


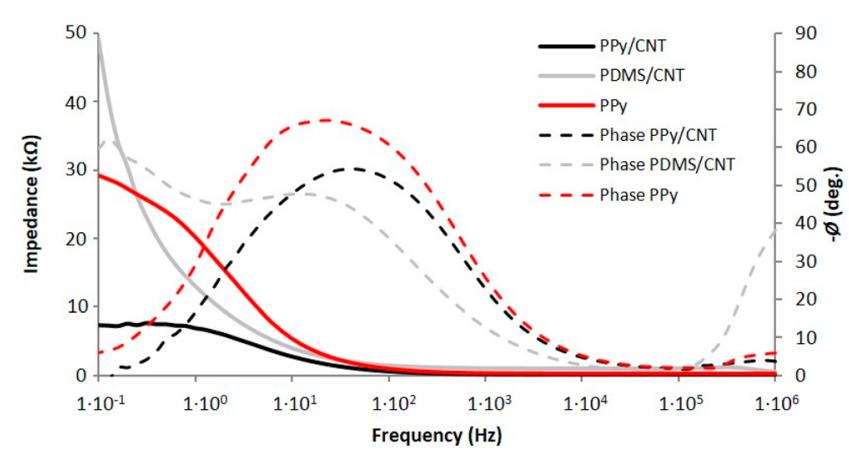

Figure 9. Impedance measurement (left axis, solid lines) and phase (right axis, dashed lines) vs frequency plot for average PPy/CNT (black), PPy (red) and PDMS/CNT (gray) scaffolds.

conducting electronic bridges between the CNT and the polymeric matrix. Furthermore, it is known that the decreased impedance of the PPy layers are due to the presence of electronic and ionic pathways. However, this kind of connections are not present in the PDMS/CNT scaffold due to the non-conductive nature of PDMS, nor in the PPy scaffold, where no CNTs have been incorporated. At the same time, bode plot data (Figure 9) displays a clear difference in the maximum phase angle between the scaffolds analyzed, exhibiting an increase in the maximum value of the capacitance: $\varphi_{\mathrm{PPy} / \mathrm{CNT}}=-54^{\circ}, \varphi_{\mathrm{PPy}}=-67^{\circ}$ and $\varphi_{\mathrm{PDMS} / \mathrm{CNT}}=$ $-62^{\circ}$. Furthermore, the phase shape of PPy and PPy/CNT scaffolds is similar, indicating their high conducting character and showing higher capacitances in the range of $10-100 \mathrm{~Hz}$. Besides, in our case the conductive nature of the PPy matrix provides an added value when dealing with neurons, being our physical characterization a landmark contribution to the field, as there is no precedent on $3 \mathrm{D}$ porous scaffolds made of PPy and CNT. However, there are plenty of literature data reporting electrical characterization of PPy nanocomposite films, whose conductivity was determined to be up to $600 \mathrm{~S}$. $\mathrm{cm}^{-1}$, depending on the film thickness. ${ }^{52}$

In Vitro Biocompatibility of the 3D Conductive Scaffolds. Mouse astrocytes C8-D1A were cultured on scaffolds for 2 days and in vitro cytotoxicity was analyzed using a modified Lactate Dehydrogenase (LDH) assay. This method has been reported previously to circumvent all interactions between CNTs and the insoluble formazan crystals formed in the commonly used 3-(4,5-dimethylthiazol-2-yl)-2,5-diphenyltetrazolium bromide (MTT) or conventional $\mathrm{LDH}$ viability tests and thus assessing the impact of CNT-based material on cellular survival in a straightforward and reliable manner. ${ }^{53}$ Cytosolic $\mathrm{LDH}$ is released and its activity signal was taken as a semiquantitative measurement of the number of surviving cells in the scaffolds. Once the cells are lysed, the level of absorbance of the $\mathrm{LDH}$ product correlates with the number of viable cells growing on the scaffolds. As all the scaffolds were seeded with the same number of astrocytes, differences would be attributed to the effect of the materials on cell survival. The previously reported PDMS/CNT was analyzed for comparison and PPy scaffolds were used as a blank control of the effect of the nanotubes on the scaffolds. Although the PDMS/CNT reported scaffold has shown similar porosity as our PPy/CNT scaffolds, we keep in mind that the differences in the mechanical properties and the hydrophilicity between the two structures come from the different nature of the polymer matrix and, unfortunately, cannot be dismissed. Figure 10a shows no difference between the absorbance of the PDMS/CNT and PPy seeded scaffolds, while the conjugation of PPy and CNT increases the absorbance significantly. Such observations not only demonstrate the non-citotoxicity of the scaffolds employed but also that the PPy/CNT scaffolds have an enormous positive impact on the C8-D1A growth yet in the first 2 days of culture.

In addition, confocal imaging was employed to analyze the cellular attachment to the PPy/CNT scaffold. Only live cells were stained with calcein-AM in fluorescent green after incubation in the scaffolds for 2 days. The 3D images in Figure $10 \mathrm{~b}$ show high confluence of live cells adhered to the scaffold. The adhesion and proliferation of C8-D1A cells on PDMS/CNT scaffolds was also analyzed with calcein-AM staining for comparison, showing less affinity to the PDMSbased than to the PPy-based scaffold (see Supporting Information). Furthermore, the morphology of the astrocytes was analyzed by staining their cytoskeleton with filamentous actin (F-actin, Figure 10c). Z-stacks showed a certain degree of cell penetration or cell infiltration within the range of visualization allowed by the objective working distance (up
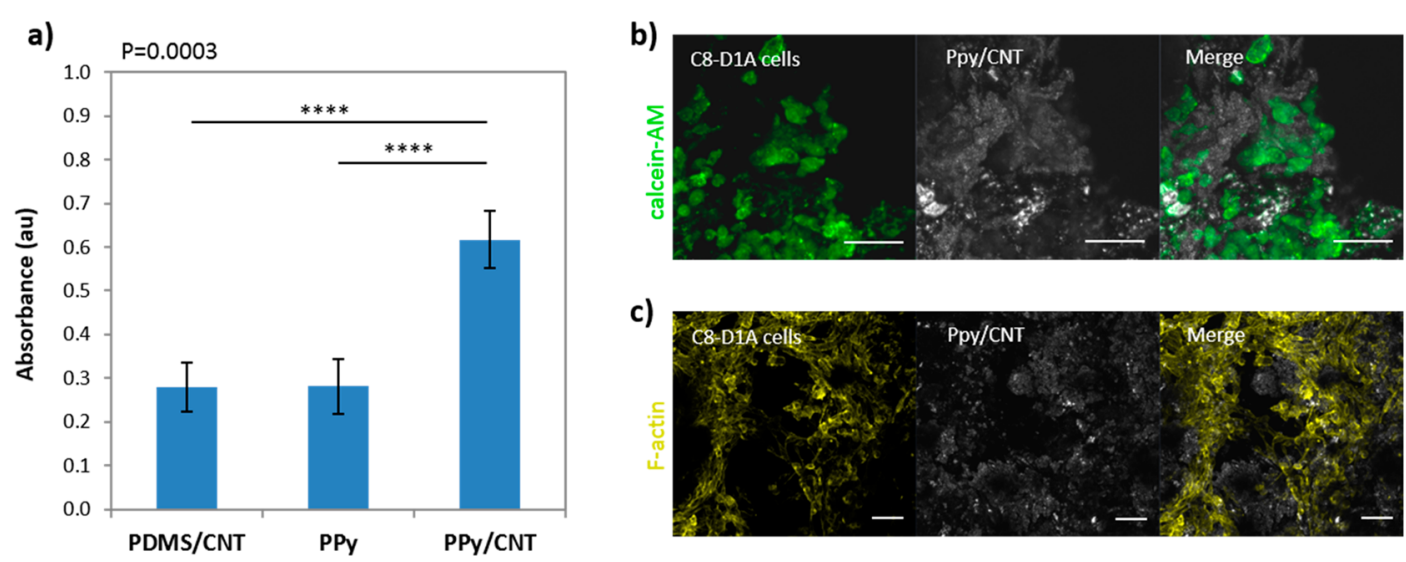

Figure 10. (a) In vitro LDH assay of C8-D1A astrocytes cultivated for $48 \mathrm{~h}$ on scaffolds in the presence or absence of CNTs. Absorbance readings for each scaffold are plotted as an average of five independent experiments $(n=4 \pm \mathrm{SD})$. Confocal images after (b) calcein-AM stain of viable cells (green) and (c) the F-actin cytoskeleton (yellow) staining of PPy/CNT scaffolds after 2 days of culture. From left to right: stained cells (green or yellow), scaffold (gray), and merge. Images are split views of Z-stacks maximum intensity projections (57 $\mu$ m optical sections). The elongated morphology of the cells indicates a good biocompatibility of the material. Scale bar $=50 \mu \mathrm{m}$. Statistical analysis with ANOVA. 
to $160 \mu \mathrm{m}$ ) through the pores of the scaffold (see Supporting Information). Large elongations as well as abundant cell-to-cell contacts are clearly distinguished on the scaffold surface, suggesting the low cytotoxicity of the material, being the cells able to maintain their normal morphology, and, as we anticipated, their function.

Finally, time-course viability of the astrocytes in the CNTs scaffolds was also analyzed. Briefly, 5000 C8-D1A cells were seeded on sterile PPy/CNT or PDMS/CNT scaffolds and cultured for 6 days. Calcein-AM staining (Figure 11) revealed

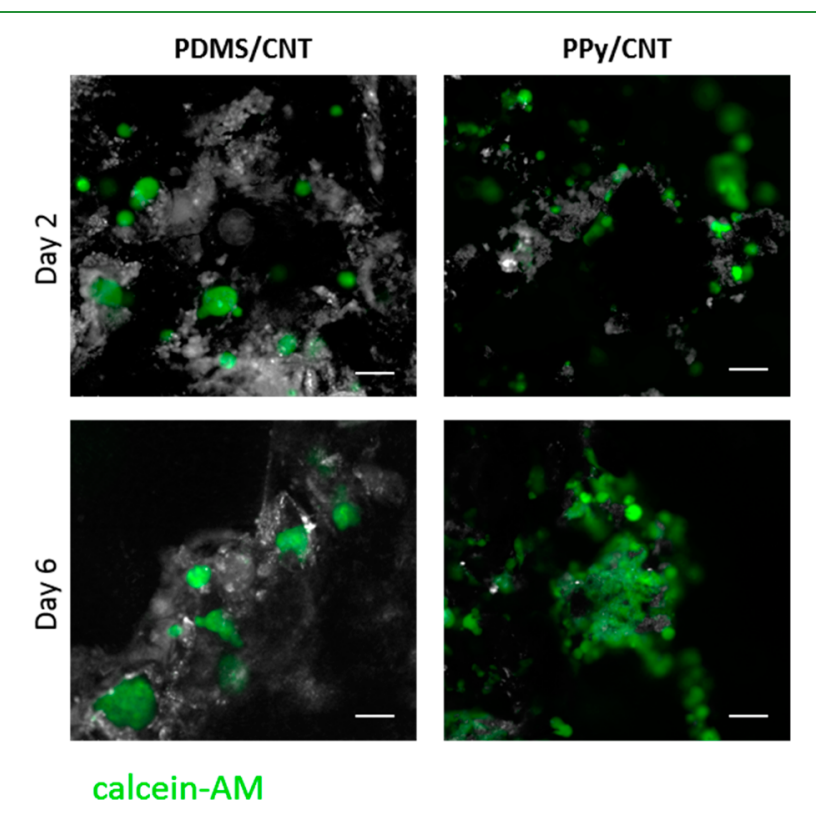

Figure 11. Confocal images after calcein-AM stain of viable cells (green) of PDMS/CNT (left) and PPy/CNT (right) scaffolds after 2 and 6 days of culture. Scale bar $=50 \mu \mathrm{m}$.

an impressive growth and invasion progression for the PPy/ $\mathrm{CNT}$, while for the PDMS/CNT astrocyte growth was not so significant. In summary, all the above-mentioned results demonstrate the outstanding ability of PPy/CNT scaffolds in astrocytic regeneration, thus suggesting its high potential as neural protheses.

\section{CONCLUSIONS}

In summary, we developed 3D scaffolds composed exclusively of CNTs and PPy to promote the growth of cells in the three dimensions, specifically designed with the chemical and physical properties to mimic the biological environment. This is the first time a conductive polymer is employed to build-up a self-standing 3D structure with CNTs. PPy was polymerized through VPP within the macrocavities of a previously manufactured template containing CNTs; by controlling the reaction conditions we were able to adjust the desired amount of polymer introduced in the scaffold. TEM revealed how the PPy layers formed adhere to the CNTs and maintain the 3D structure of the whole system. As well, it seems that some of the CNTs might be coated with a thin layer of the polymer, which would favor the underpinning effect within the entire system.

SEM and $\mu$-CT analyses show the homogeneous internal structure of the final devices, mainly composed of emptiness and macro-cavities principally between 50 and $200 \mu \mathrm{m}$, large enough to accommodate any kind of cell or biological entity.
Besides, this porous morphology allows a significantly higher surface-to-volume ratio, resulting in low impedance, and being the key feature of these manufactured devices the improved tridimensional conductivity with respect to the previously reported PDMS-based scaffolds. ${ }^{6}$ Furthermore, mechanical properties were evaluated by compression, and the resulting Young's Modulus (YM) was observed to be exponentially related to the amount of polymer present and in a significant part of samples studied the modulus approached to that of brain tissue. Finally, biocompatibility was evaluated by culturing C8-D1A astrocytes inside the scaffolds with YM similar to the biological tissue, i. e., scaffolds with the lower amount of PPy. Surprisingly, after $48 \mathrm{~h}$ of incubation the $\mathrm{PPy} / \mathrm{CNT}$ architectures showed a huge stimulation effect in the cell growth, regeneration, and shape, which was maintained after larger periods of culture. Such effect is not only caused by the presence of CNTs, but also to the use of a conductive polymer as a matrix of the scaffold. In conclusion, we hypothesize that the incorporation of CNTs not only affects the conductivity of the $3 \mathrm{D}$ structures, but also may change their properties making them a completely different material.

Overall, we demonstrated that the hereby presented scaffolds fulfill all the requirements for the successful growth, development and regeneration of conductive cells. Their tridimensional structure, high conductivity, homogeneous internal structure and porosity, together with their outstanding biocompatibility and cell-growth ability, place this smart material among the most promising next-generation scaffolds for electroactive tissue prostheses. In a subsequent stage of this study, we plan to perform functional assays to validate whether there is an effect of interest to pursue this material for its final application. Thus, we will analyze further the activity and behavior of the cells, including protein secretion and gene expression, among others, and using other kind of electroactive cells, as well as the growth potential on primary cells by in vivo implantation of the scaffolds in an injured spinal cord. We will also develop further strategies and scaffolds with lower YM for application in brain and cardiac tissues.

\section{ASSOCIATED CONTENT}

\section{Supporting Information}

The Supporting Information is available free of charge on the ACS Publications website at DOI: 10.1021/acsami.8b16462.

Photographs of the cell device manufactured for the conductivity measurements, XPS analyses, cyclic compression graphs, and supplementary TGA plots and data, SEM images, $\mu \mathrm{CT}$ analyses, and in vitro assays (Zstacks) (PDF)

\section{AUTHOR INFORMATION}

\section{Corresponding Authors}

*(N.A.) E-mail: nuria.alegret@ehu.eus.

*(D.M.) E-mail: david.mecerreyes@ehu.es.

*(M.P.) E-mail: prato@units.it.

ORCID

Nuria Alegret: 0000-0002-8329-4459

Antonio Dominguez-Alfaro: 0000-0002-3215-9732

Jose M. González-Domínguez: 0000-0002-0701-7695

Blanca Arnaiz: 0000-0001-5789-0321

Unai Cossío: 0000-0002-3248-8683

Susanna Bosi: 0000-0001-7863-9144 
Ester Vázquez: 0000-0003-3223-8024

Pedro Ramos-Cabrer: 0000-0003-0368-7031

David Mecerreyes: 0000-0002-0788-7156

Maurizio Prato: 0000-0002-8869-8612

\section{Present Addresses}

$\nabla$ (N.A.) Cardiovascular Institute, School of Medicine, Division of Cardiology, University of Colorado Denver Anschutz Medical Campus, 12700 E. 19th Avenue, Bldg. P15, Aurora, CO, 80045, USA.

O(J.M.G.D.) Group of Carbon Nanostructures and Nanotechnology, Instituto de Carboquimica ICB-CSIC, C/Miguel Luesma Castán 4, 50018 Zaragoza Spain.

\section{Author Contributions}

The manuscript was written through contributions of all authors. All authors have given approval to the final version of the manuscript.

\section{Funding}

M.P. received funding from the Spanish Ministry of Economy and Competitiveness MINECO (project CTQ2016-76721-R), Diputación Foral de Gipuzkoa program Red (101/16), and ELKARTEK bmG2017 (ref: Elkartek KK-2017/00008. BOPV resolution: $8 \mathrm{Feb} 2018$ ). N.A. has received funding from the European Union's Horizon 2020 research and innovation program under the Marie Sklodowska-Curie Grant Agreement 753293, acronym NanoBEAT

\section{Notes}

The authors declare no competing financial interest.

\section{ACKNOWLEDGMENTS}

We acknowledge Donato Mancino for the support given during the revision stage. As well, AXA Research Fund and University of Trieste are gratefully acknowledged.

\section{ABBREVIATIONS}

VPP, vapor phase polymerization, CP conductive polymer; CNTs, carbon nanotubes; PPy, polypyrrole.

\section{REFERENCES}

(1) EU Joint Programme - Neurodegenerative Disease Research (JPND). http://www.neurodegenerationresearch.eu/about/what/ (accessed May 22, 2018).

(2) Kandel, E. R.; Schwartz, J. H.; Jessel, T. M.; Siegelbaum, S. A.; Hudspeth, A. J. Principles of Neural Science, 5th ed.; McGraw Hill: Appleton and Lange, 2006.

(3) Navarro, X.; Vivó, M.; Valero-Cabré, A. Neural plasticity after peripheral nerve injury and regeneration. Prog. Neurobiol. 2007, 82 (4), 163-201.

(4) Sundelacruz, S.; Levin, M.; Kaplan, D. L. Role of Membrane Potential in the Regulation of Cell Proliferation and Differentiation. Stem Cell Rev. 2009, 5 (3), 231-246.

(5) Fabbro, A.; Prato, M.; Ballerini, L. Carbon Nanotubes in Neuroregeneration and Repair. Adv. Drug Delivery Rev. 2013, 65 (15), 2034-2044.

(6) Bosi, S.; Rauti, R.; Laishram, J.; Turco, A.; Lonardoni, D.; Nieus, T.; Prato, M.; Scaini, D.; Ballerini, L. From 2D to 3D: Novel Nanostructured Scaffolds to Investigate Signalling in Reconstructed Neuronal Networks. Sci. Rep. 2015, 5, 9562.

(7) Gilmore, J. L.; Yi, X.; Quan, L.; Kabanov, A. V. Novel Nanomaterials for Clinical Neuroscience. J. Neuroimmune Pharmacol. 2008, 3 (2), 83-94.

(8) Keefer, E. W.; Botterman, B. R.; Romero, M. I.; Rossi, A. F.; Gross, G. W. Carbon Nanotube Coating Improves Neuronal Recordings. Nat. Nanotechnol. 2008, 3 (7), 434-439.
(9) Kotov, N. A.; Winter, J. O.; Clements, I. P.; Jan, E.; Timko, B. P.; Campidelli, S.; Pathak, S.; Mazzatenta, A.; Lieber, C. M.; Prato, M.; Bellamkonda, R. V.; Silva, G. A.; Kam, N. W. S.; Patolsky, F.; Ballerini, L. Nanomaterials for Neural Interfaces. Adv. Mater. 2009, 21 (40), $3970-4004$.

(10) Lee, W.; Parpura, V.; et al. Wiring Neurons with Carbon Nanotubes. Front. Neuroeng. 2009, $2,8$.

(11) Shein, M.; Greenbaum, A.; Gabay, T.; Sorkin, R.; David-Pur, M.; Ben-Jacob, E.; Hanein, Y. Engineered Neuronal Circuits Shaped and Interfaced with Carbon Nanotube Microelectrode Arrays. Biomed. Microdevices 2009, 11 (2), 495-501.

(12) Malarkey, E. B.; Parpura, V. Carbon Nanotubes in Neuroscience. Acta Neurochir. Suppl. 2010, 106, 337-341.

(13) Fabbro, A.; Villari, A.; Laishram, J.; Scaini, D.; Toma, F. M.; Turco, A.; Prato, M.; Ballerini, L. Spinal Cord Explants Use Carbon Nanotube Interfaces To Enhance Neurite Outgrowth and To Fortify Synaptic Inputs. ACS Nano 2012, 6 (3), 2041-2055.

(14) Marchesan, S.; Ballerini, L.; Prato, M. Nanomaterials for Stimulating Nerve Growth. Science 2017, 356 (6342), 1010-1011.

(15) Wu, Y.; Wang, L.; Guo, B.; Shao, Y.; Ma, P. X. Electroactive Biodegradable Polyurethane Significantly Enhanced Schwann Cells Myelin Gene Expression and Neurotrophin Secretion for Peripheral Nerve Tissue Engineering. Biomaterials 2016, 87, 18-31.

(16) Martinez-Hernandez, A. L.; Velasco-Santos, C.; Castano, V. M. Carbon Nanotubes Composites: Processing, Grafting and Mechanical and Thermal Properties. Curr. Nanosci. 2010, 6 (1), 12-39.

(17) Guo, B.; Ma, P. X. Conducting Polymers for Tissue Engineering. Biomacromolecules 2018, 19 (6), 1764-1782.

(18) George, P. M.; Lyckman, A. W.; LaVan, D. A.; Hegde, A.; Leung, Y.; Avasare, R.; Testa, C.; Alexander, P. M.; Langer, R.; Sur, M. Fabrication and Biocompatibility of Polypyrrole Implants Suitable for Neural Prosthetics. Biomaterials 2005, 26 (17), 3511-3519.

(19) Cellot, G.; Lagonegro, P.; Tarabella, G.; Scaini, D.; Fabbri, F.; Iannotta, S.; Prato, M.; Salviati, G.; Ballerini, L. PEDOT:PSS Interfaces Support the Development of Neuronal Synaptic Networks with Reduced Neuroglia Response In vitro. Front. Neurosci. 2016, 9, 521.

(20) Bauquier, S. H.; McLean, K. J.; Jiang, J. L.; Boston, R. C.; Lai, A.; Yue, Z.; Moulton, S. E.; Halliday, A. J.; Wallace, G.; Cook, M. J. Evaluation of the Biocompatibility of Polypyrrole Implanted Subdurally in GAERS. Macromol. Biosci. 2017, 17 (5), 1600334.

(21) Balint, R.; Cassidy, N. J.; Cartmell, S. H. Conductive Polymers: towards a Smart Biomaterial for Tissue Engineering. Acta Biomater. 2014, 10 (6), 2341-2353.

(22) Mantione, D.; Del Agua, I.; Schaafsma, W.; Diez-Garcia, J.; Castro, B.; Sardon, H.; Mecerreyes, D. Poly(3,4-ethylenedioxythiophene):GlycosAminoGlycan Aqueous Dispersions: Toward Electrically Conductive Bioactive Materials for Neural Interfaces. Macromol. Biosci. 2016, 16 (8), 1227-1238.

(23) Guarino, V.; Zuppolini, S.; Borriello, A.; Ambrosio, L. ElectroActive Polymers (EAPs): A Promising Route to Design Bio-Organic/ Bioinspired Platforms with on Demand Functionalities. Polymers 2016, 8 (5), 185.

(24) Pelto, J.; Bjorninen, M.; Palli, A.; Talvitie, E.; Hyttinen, J.; Mannerstrom, B.; Suuronen Seppanen, R.; Kellomaki, M.; Miettinen, S.; Haimi, S. Novel Polypyrrole-Coated Polylactide Scaffolds Enhance Adipose Stem Cell Proliferation and Early Osteogenic Differentiation. Tissue Eng., Part A 2013, 19 (7-8), 882-892.

(25) Mihailescu, M.; Popescu, R. C.; Matei, A.; Acasandrei, A.; Paun, I. A.; Dinescu, M. Investigation of Osteoblast Cells Behavior in Polymeric 3D Micropatterned Scaffolds using Digital Holographic Microscopy. Appl. Opt. 2014, 53 (22), 4850-4858.

(26) Lee, J. Y.; Bashur, C. A.; Goldstein, A. S.; Schmidt, C. E. Polypyrrole-coated electrospun PLGA nanofibers for neural tissue applications. Biomaterials 2009, 30 (26), 4325-4335.

(27) Hernández-Ferrer, J.; Pérez-Bruzón, R. N.; Azanza, M. J.; González, M.; Moral, R.; Ansón-Casaos, A.; Fuente, J. M.; Marijuan, P. C.; Martínez, M. T. Study of Neuron Survival on Polypyrroleembedded Single-walled Carbon Nanotube Substrates for Long-term 
Growth Conditions. J. Biomed. Mater. Res., Part A 2014, 102 (12), $4443-4454$

(28) Jin, L.; Feng, Z. Q.; Zhu, M. L.; Wang, T.; Leach, M. K.; Jiang, Q. A Novel Fluffy Conductive Polypyrrole Nano-Layer Coated PLLA Fibrous Scaffold for Nerve Tissue Engineering. J. Biomed. Nanotechnol. 2012, 8 (5), 779-785.

(29) Zanjanizadeh Ezazi, N.; Shahbazi, M. A.; Shatalin, Y. V.; Nadal, E.; Mäkilä, E.; Salonen, J.; Kemell, M.; Correia, A.; Hirvonen, J.; Santos, H. A. Conductive vancomycin-loaded mesoporous silica polypyrrole-based scaffolds for bone regeneration. Int. J. Pharm. 2018, $536(1), 241-250$.

(30) Xu, Q.; Jin, L.; Li, C.; Kuddannayai, S.; Zhang, Y. The Effect of Electrical Stimulation on Cortical Cells in 3D Nanofibrous Scaffolds. RSC Adv. 2018, 8 (20), 11027-11035.

(31) Choi, J. S.; Park, J. S.; Kim, B.; Lee, B.-T.; Yim, J.-H. In vitro biocompatibility of vapour phase polymerised conductive scaffolds for cell lines. Polymer 2017, 124, 95-100.

(32) Björninen, M.; Gilmore, K.; Pelto, J.; Seppänen-Kaijansinkko, R.; Kellomäki, M.; Miettinen, S.; Wallace, G.; Grijpma, D.; Haimi, S. Electrically Stimulated Adipose Stem Cells on Polypyrrole-Coated Scaffolds for Smooth Muscle Tissue Engineering. Ann. Biomed. Eng. 2017, 45 (4), 1015-1026.

(33) Sajesh, K. M.; Jayakumar, R.; Nair, S. V.; Chennazhi, K. P. Biocompatible conducting chitosan/polypyrrole-alginate composite scaffold for bone tissue engineering. Int. J. Biol. Macromol. 2013, 62, 465-471.

(34) Zhang, J.; Li, M.; Kang, E.-T.; Neoh, K. G. Electrical stimulation of adipose-derived mesenchymal stem cells in conductive scaffolds and the roles of voltage-gated ion channels. Acta Biomater. 2016, 32, 46-56.

(35) Tu, X.; Xie, Q.; Jiang, S.; Yao, S. Electrochemical Quartz Crystal Impedance Study on the Overoxidation of PolypyrroleCarbon Nanotubes Composite Film for Amperometric Detection of Dopamine. Biosens. Bioelectron. 2007, 22 (12), 2819-2826.

(36) Georgakilas, V.; Dallas, P.; Niarchos, D.; Boukos, N.; Trapalis, C. Polypyrrole/MWNT Nanocomposites Synthesized through Interfacial Polymerization. Synth. Met. 2009, 159 (7-8), 632-636.

(37) Liu, F.; Han, G.; Chang, Y.; Fu, D.; Li, Y.; Li, M. Fabrication of carbon nanotubes/polypyrrole/carbon nanotubes/melamine foam for supercapacitor. J. Appl. Polym. Sci. 2014, 131 (2), 39779.

(38) Santos, M. R. d.; Oliveira, H. P. d. Simple Method for Mass Production of Polypyrrole/Carbon Nanotubes Hybrid Artificial Muscle. Quim. Nova 2014, 1000-1003.

(39) Jousse, F.; Olmedo, L. Parametric Study of Vapor-Phase Polymerization of Pyrrole: An Improvement in Reproducibility. Synth. Met. 1991, 41 (1), 385-388.

(40) Zhou, T.; Ming, Y.; Perry, S. F.; Tatic-Lucic, S. Estimation of the physical properties of neurons and glial cells using dielectrophoresis crossover frequency. J. Biol. Phys. 2016, 42 (4), 571-586.

(41) Aurand, E. R.; Usmani, S.; Medelin, M.; Scaini, D.; Bosi, S.; Rosselli, F. B.; Donato, S.; Tromba, G.; Prato, M.; Ballerini, L. Nanostructures to Engineer 3D Neural-Interfaces: Directing Axonal Navigation toward Successful Bridging of Spinal Segments. Adv. Funct. Mater. 2018, 28 (12), 1700550.

(42) Ali-Boucetta, H.; Al-Jamal, K. T.; Müller, K. H.; Li, S.; Porter, A. E.; Eddaoudi, A.; Prato, M.; Bianco, A.; Kostarelos, K. Cellular Uptake and Cytotoxic Impact of Chemically Functionalized and Polymer-Coated Carbon Nanotubes. Small 2011, 7 (22), 3230-3238.

(43) Martín, C.; Merino, S.; González-Domínguez, J. M.; Rauti, R.; Ballerini, L.; Prato, M.; Vázquez, E. Graphene Improves the Biocompatibility of Polyacrylamide Hydrogels: 3D Polymeric Scaffolds for Neuronal Growth. Sci. Rep. 2017, 7 (1), 10942.

(44) Budday, S.; Nay, R.; de Rooij, R.; Steinmann, P.; Wyrobek, T.; Ovaert, T. C.; Kuhl, E. Mechanical Properties of Gray and White Matter Brain Tissue by Indentation. J. Mech. Behav. Biomed. Mater. 2015, 46, 318-330.

(45) Karimi, A.; Shojaei, A.; Tehrani, P. Mechanical Properties of the Human Spinal Cord Under the Compressive Loading. J. Chem. Neuroanat. 2017, 86, 15-18.
(46) Rivnay, J.; Inal, S.; Collins, B. A.; Sessolo, M.; Stavrinidou, E.; Strakosas, X.; Tassone, C.; Delongchamp, D. M.; Malliaras, G. G. Structural Control of Mixed Ionic and Electronic Transport in Conducting Polymers. Nat. Commun. 2016, 7, 11287.

(47) Wang, S.; Guan, S.; Xu, J.; Li, W.; Ge, D.; Sun, C.; Liu, T.; Ma, $X$. Neural stem cell proliferation and differentiation in the conductive PEDOT-HA/Cs/Gel scaffold for neural tissue engineering. Biomater. Sci. 2017, 5 (10), 2024-2034.

(48) Wei, B.; Liu, J.; Ouyang, L.; Martin, D. C. POSS-ProDOT Crosslinking of PEDOT. J. Mater. Chem. B 2017, 5 (25), 5019-5026.

(49) Wan, A. M. D.; Inal, S.; Williams, T.; Wang, K.; Leleux, P.; Estevez, L.; Giannelis, E. P.; Fischbach, C.; Malliaras, G. G.; Gourdon, D. 3D Conducting Polymer Platforms for Electrical Control of Protein Conformation and Cellular Functions. J. Mater. Chem. B 2015, 3 (25), 5040-5048.

(50) Inal, S.; Hama, A.; Ferro, M.; Pitsalidis, C.; Oziat, J.; Iandolo, D.; Pappa, A. M.; Hadida, M.; Huerta, M.; Marchat, D.; Mailley, P.; Owens, R. M. Conducting Polymer Scaffolds for Hosting and Monitoring 3D Cell Culture. Adv. Biosyst. 2017, 1 (6), 1700052.

(51) Dong, S.-L. 3D Printing of Aniline Tetramer-GraftedPolyethylenimine and Pluronic F127 Composites for Electroactive Scaffolds. Macromol. Rapid Commun. 2017, 38 (4), 1600551.

(52) Kim, J.; Sohn, D.; Sung, Y.; Kim, E.-R. Fabrication and Characterization of Conductive Polypyrrole Thin Film Prepared by in situ Vapor-Phase Polymerization. Synth. Met. 2003, 132 (3), 309313.

(53) Ali-Boucetta, H.; Al-Jamal, K. T.; Kostarelos, K., Cytotoxic Assessment of Carbon Nanotube Interaction with Cell Cultures. In Biomedical Nanotechnology: Methods and Protocols; Hurst, S. J., Ed. Humana Press: Totowa, NJ, 2011; pp 299-312. 